\title{
Editorial: Cerebral Palsy: New Developments
}

\author{
Antigone Papavasiliou ${ }^{1 *}$, Hilla Ben-Pazi ${ }^{2}$, Sotiria Mastroyianni ${ }^{3}$ and Els Ortibus ${ }^{4,5}$ \\ ${ }^{1}$ Department of Pediatric Neurology, laso Children's Hospital, Marousi, Greece, ${ }^{2}$ Department of Pediatric Orthopedics, \\ Assuta Ashdod Hospital, Ashdod, Israel, ${ }^{3}$ Department of Pediatric Neurology, Pan and Aglaia Kyriakou Children's Hospital, \\ Athens, Greece, ${ }^{4}$ Department of Development and Regeneration, KU Leuven, Leuven, Belgium, ${ }^{5}$ Department of Pediatric \\ Neurology, University Hospitals Leuven, Leuven, Belgium
}

Keywords: cerebral palsy, epidemiology, neuroimaging, genetics, development, ethics, muscle

\author{
Editorial on the Research Topic
}

Cerebral Palsy: New Developments

\section{DEFINITION AND ETIOLOGY}

Cerebral palsy $(\mathrm{CP})$ is defined as a non-progressive permanent disorder of movement and posture attributed to disturbances in the developing fetal and infant brain (1). Diagnosis is based on clinical signs, not on causation. This definition was not modified when brain MRI demonstrated diverse lesions underlying CP phenotypes in $80 \%$ of patients $(2,3)$, nor when the development of a semi-quantitative scale (4) led to studies on CP characteristics, localization, extent, and severity of the brain lesions. Possible amplification and clarification of the definition is under discussion.

Genetic studies revealed that half of CP cases without environmental risk factors have pathogenic genomic deletions or duplications (5) raising questions whether this definition could withstand the discovery of mutations that disrupt brain development and confer risk for CP (6). For example, Beysen et al. reported three patients with spastic CP and genetically confirmed Aicardi-Goutières syndrome. MacLennan et al. argued that similarly to the diagnosis of epilepsy the clinical diagnosis of CP should remain, but prompt appropriate genetic investigation (7). Lewis et al., based on CP genomic data, proposed criteria for CP-associated genes through gene discovery, laboratory research, and clinical application. Horber et al., provided guidance for searching for genetic etiologies based on neuroimaging from the SCPE database. Predominantly white and gray matter injuries (around 50 and 20\%, respectively) are considered acquired; genetic factors may increase vulnerability and are considered with positive family history and/or missing causative external factors. In maldevelopments and non-specific/normal findings (around 11\% each), monogenic causes are likely. In miscellaneous MRI findings, a possible genetic origin may be considered. Wu F. et al. analyzed the most cited imaging articles in CP over three decades and concluded that multi-modality neuroimaging and high-level evidence-based methodologies could be used in future research to further elucidate pathophysiology, prognosis and efficacy of proposed treatments. Reviews emphasized the need for uniform procedures of MRI classification (8), image acquisition, and common outcome measures $(9,10)$. A common data language for research, such as the common data elements for CP proposed by the AACPDM, will facilitate comparison between studies (11).

\section{EPIDEMIOLOGY}

CP prevalence remained relatively stable over several decades; fluctuations reflected advanced perinatal and neonatal care. A decrease in the overall prevalence was preceded by reports on 
decreasing prevalence in low BW children (12-16). Also, severe $\mathrm{CP}$ prevalence is declining in preterm and low BW children with severity remaining unchanged in those extremely preterm or with very low BW $(12,13)$. Tracking the prevalence and clinical features of patients with $\mathrm{CP}$ is inherently related to the quality and amount of the collected data (17). Therefore, data from large population-based registries are valuable. Arnaud et al. examined the prevalence and severity of CP in 2,273 preterms, birth-years 2004-2010, from 12 population-based European registries; CP prevalence decreased except for extremely immature children, with the most severely affected showing a similar trend.

Of particular interest are the moderately and late preterm infants (32-34 and 34-36 weeks GA, respectively) representing the majority of all preterms (18) with higher risk than term infants in mortality, poor short-term and long-term outcomes, including impaired motor function (19). Smyrni et al. reported outcomes of a cohort of moderately and late preterm infants (191 out of 1,016 with CP), derived from a population-based registry. Moderately preterm-born with CP were more likely to have a history of N-ICU admission and require respiratory support than late preterm neonates. BW was a strong predictor for early neonatal problems in both groups. The majority in both groups had bilateral spastic CP, white matter lesions and comparable GMFCS levels.

\section{FUNCTIONAL DEFICITS}

Spastic CP is the prevailing type and the most amenable to treatment. Main neural impairments characterizing spastic CP include spasticity, decreased selective muscle control and poor postural stability. Secondary non-neural musculoskeletal impairments are altered intrinsic muscle structure, muscle contractures, and bony deformities. Muscle weakness is a predominant impairment highly associated with functional disability that depends both on neural activity and on intrinsic muscle structure. In fact, weakness and contractures are significant contributors to motor deficits and progressive disability with growth, characterizing this condition.

Hanssen et al., discussed the disproportional decrease of muscle size and strength around the knee and ankle joints in spastic CP and highlighted the large variability in the contribution of muscle size to muscle weakness. In a crosssectional study of the development of lower limb strength in 160 ambulatory patients with bilateral spastic CP and 86 typically developing controls, aged 7-16 years, Darras et al., showed that patients exhibited lower strength values in lower limbs than controls, more pronounced in the severely impaired. A pattern of strength imbalance between antagonistic muscle groups was documented in all ages suggesting that strength imbalances are inherent to $\mathrm{CP}$ early on and do not develop with age.

De Beukelaer et al. compared medial gastrocnemius characteristics in Hereditary Spastic Paraparesis and Bilateral Spastic CP and found in both significantly smaller muscle volumes compared to controls concluding that treatment in these two conditions does not have to be different.

Altered muscle structure in CP relates to the pathophysiology of muscle contractures. Howard and Herzog review basic science and imaging studies which provide explanations for muscle stiffness and decreased muscle volume and length in CP. Concerns are expressed on the effect of botulinum toxin on muscle histology based on findings from preclinical animal models. It should be noted that no data exist on muscle histopathological alterations following other spasticity treatments such as, physiotherapy, orthoses, Intrathecal Baclofen and Selective Dorsal Rhizotomies.

Cognitive dysfunction is equally challenging as motor impairment but less studied. Intellectual disability epidemiology as related to imaging and clinical phenomenology is systematically monitored in large CP registries $(20,21)$. Himmelmann et al. examined structure-function relationships based on MRIs from 3,818 patients with CP (birth-years 19992009), from 20 European registers. The Impairment Index (22) showed worse associations of bilateral than unilateral compromise with motor impairment, intellectual disability, vision and hearing impairment and epilepsy. Associations between extent and localization of brain lesions and cognitive function are examined but heterogeneity of cognitive findings with similar MRI lesions and the effects of early brain plasticity raise questions as to the utility of this approach. Few studies assessed cognitive profiles or developmental trajectories of cognition in children with $\mathrm{CP}(23,24)$. Intellectual disability is often overestimated. Tests need to be adapted so that cognition can be reliably assessed, especially in very young children and those with severe speech and motor impairments. Visual-spatial abilities, language and executive functions have been reported on, but other determinants of cognition, such as memory, are less studied $(24,25)$. In bilateral spastic CP uneven cognitive profiles to the advantage of verbal potential are shown; lower performance IQ is attributed to lower visual-spatial reasoning. Visual - perceptual impairment is reported in children with lower cognitive functioning, but also with normal cognition, unrelated to non-verbal cognitive functioning $(26,27)$.

\section{NEW MANAGEMENT TRENDS}

Treatments performed outside a rehabilitation setting gain popularity emphasizing the importance of parent empowerment in caring for their children. Constraint-induced movement therapy in unilateral CP is a program with proven efficacy given in the home environment or during intensive "camp" sessions (28). Wu C-L. et al. demonstrated feasibility of this program in preschool after botulinum toxin injections with improvements in self-care and hand function.

The need for caution in overestimating the abilities of children when tested in controlled environments is discussed. Wiedmann et al., illustrate the feasibility of measuring walking speed in children with $\mathrm{CP}$ with 3D accelerometers in real life and show that generally, patients and controls walk slower in a natural environment than in the lab. 
During the COVID-19 outbreak remote assessments and treatments proved helpful but underutilized (29-31). The need to set up such initiatives increased (32). Telemedicine became the main communication route between care providers, patients and caregivers. Ben-Pazi et al. describe the accelerated telemedicine impact during the pandemic in $\mathrm{CP}$ care in terms of clinical accessibility, continuity of care, prevention, multidisciplinary approach, and participation. Studies need to examine if teleservices can prevent/reduce long-term comorbidities such as hip dislocation.

Technology has changed the scene for the treatment of $\mathrm{CP}$ however, some patients with painful syndromes may not be treated with advanced surgical procedures and palliative techniques may be required. Pain affects patients' quality of life and becomes challenging for patients, families, and physicians. Koch et al. presented four palliative options for severely painful spastic hip dislocation, in those with contraindications for reconstructive surgery. Case studies and technique comparisons show how old approaches can become new trends with high acceptability by patients and families.

Technological advances and societal changes create new ethical dilemmas for those involved in the care of patients with CP. Dan reviews principles of clinical bioethics and provides a theoretical approach toward organization of the clinician's thinking process and a constructive dialogue with patients and families.

\section{REFERENCES}

1. Rosenbaum P, Paneth N, Leviton A, Goldstein M, Bax M, Damiano D, et al. A report: the definition and classification of cerebral palsy April 2006. Dev Med Child Neurol Suppl. (2007)109:8-14. doi: 10.1111/j.1469-8749.2007.tb12610.x

2. Krägeloh-Mann I, Horber V. The role of magnetic resonance imaging in elucidating the pathogenesis of cerebral palsy: a systematic review. Dev Med Child Neurol. (2007) 49:144-51. doi: 10.1111/j.1469-8749.2007.00144.x

3. Korzeniewski SJ, Birbeck G, DeLano MC, Potchen MJ, Paneth N. A systematic review of neuroimaging for cerebral palsy. J Child Neurol. (2008) 23:216-27. doi: $10.1177 / 0883073807307983$

4. Fiori S, Cioni G, Klingels K, Ortibus E, Van Gestel L, Rose S, et al. Reliability of a novel, semi-quantitative scale for classification of structural brain magnetic resonance imaging in children with cerebral palsy. Dev Med Child Neurol. (2014) 56:839-45. doi: 10.1111/dmcn.12457

5. Segel R, Ben-Pazi H, Zeligson S, Fatal-Valevski A, Aran A, Gross-Tsur V, et al. Copy number variations in cryptogenic cerebral palsy. Neurology. (2015) 84:1660-8. doi: 10.1212/WNL.0000000000001494

6. Jin SC, Lewis SA, Bakhtiari S, Zeng X, Sierant MC, Shetty S, et al. Mutations disrupting neuritogenesis genes confer risk for cerebral palsy. Nat Genet. (2020) 52:1046-56. doi: 10.1038/s41588-020-0695-1

7. MacLennan AH, Lewis S, Moreno-De-Luca A, Fahey M, Leventer RJ, McIntyre S, et al. Genetic or other causation should not change the clinical diagnosis of cerebral palsy. J Child Neurol. (2019) 34:472-6. doi: $10.1177 / 0883073819840449$

8. Himmelmann K, Horber V, de la Cruz J, Horridge K, Mejaski-Bosnjak V, Hollody K, et al. MRI classification system (MRICS) for children with cerebral palsy: development, reliability and recommendations. Dev Med Child Neurol. (2017) 59:57-64. doi: 10.1111/dmcn.13166

9. Franki I, Mailleux L, Emsell L, Peedima ML, Fehrenbach A, Feys H, et al. The relationship between neuroimaging and motor outcome in children with cerebral palsy: a systematic review - Part A. Structural imaging. Res Dev Disabil. (2020) 100:103606. doi: 10.1016/j.ridd.2020.103606

\section{CONCLUSION}

$\mathrm{CP}$, the most common cause of childhood disability, attracts researchers from different disciplines. It is a hot topic for neuroscientists as genetic research unveils the contribution of gene mutations to causation and a promising field for the study of brain structural connectivity and plasticity during development or post-intervention. The need to further elucidate pathophysiological mechanisms in order to develop neuroprotective treatments in those at risk for $\mathrm{CP}$ remains. Lastly, research on clinical issues, interventions, and outcomes served by many different medical and therapeutic disciplines, creates a unique setting for collaborative and multifaceted work for the purpose of improving quality of life in children with $\mathrm{CP}$ and their families. As a result, $\mathrm{CP}$ attracts researchers of neurodevelopment, technology experts, as well as from the therapeutic community and remains an "old" but always challenging problem for all.

\section{AUTHOR CONTRIBUTIONS}

AP contributed to the design of the editorial, analysis and interpretation of the submitted articles, drafting of the editorial, and finalizing. SM, EO, and HB-P revisited the content, added paragraphs and relevant references. All authors read and approved the article.

10. Mailleux L, Franki I, Emsell L, Peedima ML, Fehrenbach A, Feys H, et al. The relationship between neuroimaging and motor outcome in children with cerebral palsy: a systematic review-Part B diffusion imaging and tractography. Res Dev Disabil. (2020) 97:103569. doi: 10.1016/j.ridd.2019.103569

11. Schiariti V, Fowler E, Brandenburg JE, Levey E, Mcintyre S, Sukal-Moulton $\mathrm{T}$, et al. A common data language for clinical research studies: the National Institute of Neurological Disorders and Stroke and American Academy for Cerebral Palsy and Developmental Medicine Cerebral Palsy Common Data Elements Version 1.0 recommendations. Dev Med Child Neurol. (2018) 60:976-86. doi: 10.1111/dmcn.13723

12. Sellier E, Platt MJ, Andersen GL, Krägeloh-Mann I, De La Cruz J, Cans C, et al. Decreasing prevalence in cerebral palsy: a multi-site european population-based study, 1980 to 2003. Dev Med Child Neurol. (2016) 58:8592. doi: $10.1111 / \mathrm{dmcn} .12865$

13. Reid SM, Meehan E, McIntyre S, Goldsmith S, Badawi N, Reddihough DS, et al. Temporal trends in cerebral palsy by impairment severity and birth gestation. Dev Med Child Neurol. (2016) 58 (Suppl. 2):25-35. doi: 10.1111/dmcn.13001

14. Durkin MS, Benedict RE, Christensen D, Dubois LA, Fitzgerald RT, Kirby RS, et al. Prevalence of cerebral palsy among 8-year-old children in 2010 and preliminary evidence of trends in its relationship to low birth weight. Paediatr Perinatal Epidemiol. (2016) 30:496-510. doi: 10.1111/ppe.12299

15. Galea C, Mcintyre S, Smithers-Sheedy H, Reid SM, Gibson C, Delacy M, et al. Cerebral palsy trends in Australia (1995-2009): a populationbased observational study. Dev Med Child Neurol. (2019) 61:186-93. doi: $10.1111 / \mathrm{dmcn} .14011$

16. Touyama M, Touyama J, Toyokawa S, Kobayashi Y. Trends in the prevalence of cerebral palsy in children born between 1988 and 2007 in Okinawa, Japan. Brain Dev. (2016) 38:792-9. doi: 10.1016/j.braindev.2016.03.007

17. Platt MJ. Counting cases of cerebral palsy. Dev Med Child Neurol. (2017) 59:243. doi: 10.1111/dmcn.13304

18. Lawn JE, Gravett MG, Nunes TM, Rubens CE, Stanton C. Global report on preterm birth and stillbirth ( 1 of 7$)$ : definitions, description of the burden and 
opportunities to improve data. BMC Pregnancy Childbirth. (2010) 10(Suppl. 1):S1. doi: 10.1186/1471-2393-S1-S1

19. Boyle EM, Johnson S, Manktelow B, Seaton SE, Draper ES, Smith LK, et al. Neonatal outcomes and delivery of care for infants born late preterm or moderately preterm: a prospective population-based study. Arch Dis Child Fetal Neonatal Ed. (2015) 100:F479-85. doi: 10.1136/archdischild-2014-30734

20. Reid SM, Meehan EM, Arnup SJ, Reddihough DS. Intellectual disability in cerebral palsy: a population-based retrospective study. Dev Med Child Neurol. (2018) 60:687-94. doi: 10.1111/dmcn.13773

21. Mastroyianni S, Petra M, Nikaina I, Koutsaki M, Pyrgelli M, Bouza E, et al. Correlation of intellectual ability with gestational age and pattern of brain MRI findings according to SCPE-MRICS in a population-based cohort of patients with cerebral palsy (CP). Dev Med Child Neurol. (2020) 62:S4. doi: $10.1111 /$ dmcn. 14688

22. Horber V, Fares A, Platt MJ, Arnaud C, Krägeloh-Mann I, Sellier E. Severity of cerebral palsy-the impact of associated impairments. Neuropediatrics. (2020) 51:120-128. doi: 10.1055/s-0040-1701669

23. Stadskleiv K. Cognitive functioning in children with cerebral palsy. Dev Med Child Neurol. (2020) 62:283-9. doi: 10.1111/dmcn.14463

24. Stadskleiv K, Jahnsen R, Andersen GL, von Tetzchner S. Neuropsychological profiles of children with cerebral palsy. Dev Neurorehabil. (2018) 21:108-20. doi: 10.1080/17518423.2017.1282054

25. Weierink L, Vermeulen RJ, Boyd RN. Brain structure and executive functions in children with cerebral palsy: a systematic review. Res Dev Disabil. (2013) 34:1678-88. doi: 10.1016/j.ridd.2013.01.035

26. Ortibus EL, De Cock PP, Lagae LG. Visual perception in preterm children: what are we currently measuring? Pediatr Neurol. (2011) 45:1-10. doi: 10.1016/j.pediatrneurol. 2011.02.008

27. Ortibus E, Lagae L, Casteels I, Demaerel P, Stiers P. Assessment of cerebral visual impairment with the L94 visual perceptual battery: clinical value and correlation with MRI findings. Dev Med Child Neurol. (2009) 51:209-17. doi: 10.1111/j.1469-8749.2008.03175.x

28. Novak I, Morgan C, Fahey M, Finch-Edmondson M, Galea C, Hines A, et al. State of the evidence traffic lights 2019: systematic review of interventions for preventing and treating children with cerebral palsy. Curr Neurol Neurosci Rep. (2020) 20:3. doi: 10.1007/s11910-020-1022-z
29. Hong YR, Lawrence J, Williams D Jr, Mainous A III. Population-level interest and telehealth capacity of US hospitals in response to COVID-19: crosssectional analysis of google search and national hospital survey data. JMIR Public Health Surveill. (2020) 6:e18961. doi: 10.2196/18961

30. Ignatowicz A, Atherton H, Bernstein CJ, Bryce C, Court R, Sturt J, et al. Internet videoconferencing for patient-clinician consultations in long-term conditions: a review of reviews and applications in line with guidelines and recommendations. Digit Health. (2019) 5:2055207619845831. doi: $10.1177 / 2055207619845831$

31. Kantarcigil C, Sheppard JJ, Gordon AM, Friel KM, Malandraki GA. A telehealth approach to conducting clinical swallowing evaluations in children with cerebral palsy. Res DevDisabil. (2016) 55:207-17. doi: 10.1016/j.ridd.2016.04.008

32. Prvu Bettger J, Thoumi A, Marquevich V, De Groote W, Rizzo Battistella L, Imamura $\mathrm{M}$, et al. COVID-19: maintaining essential rehabilitation services across the care continuum. BMJ Glob Health. (2020) 5:e002670. doi: 10.1136/bmjgh-2020-002670

Conflict of Interest: The authors declare that the research was conducted in the absence of any commercial or financial relationships that could be construed as a potential conflict of interest.

Publisher's Note: All claims expressed in this article are solely those of the authors and do not necessarily represent those of their affiliated organizations, or those of the publisher, the editors and the reviewers. Any product that may be evaluated in this article, or claim that may be made by its manufacturer, is not guaranteed or endorsed by the publisher.

Copyright (C) 2021 Papavasiliou, Ben-Pazi, Mastroyianni and Ortibus. This is an open-access article distributed under the terms of the Creative Commons Attribution License (CC BY). The use, distribution or reproduction in other forums is permitted, provided the original author(s) and the copyright owner(s) are credited and that the original publication in this journal is cited, in accordance with accepted academic practice. No use, distribution or reproduction is permitted which does not comply with these terms. 